\title{
Inovasi Home Care Apoteker melalui Supervisi Penggunaan Obat Geriatri untuk Meningkatkan Kepatuhan Terapi Penyakit Kronis
}

\author{
Yuhansyah Nurfauzi ${ }^{1,2}$, Djoko Wahyono ${ }^{1}$, Fita Rahmawati ${ }^{1}$, Nanang M. Yasin ${ }^{1}$ \\ ${ }^{1}$ Program Pascasarjana Fakultas Farmasi, Universitas Gadjah Mada, Yogyakarta, Indonesia, \\ ${ }^{2}$ Departemen Farmasi, STIKES Al-Irsyad Al-Islamiyyah, Cilacap, Indonesia
}

\begin{abstract}
Abstrak
Pelayanan kefarmasian di Indonesia saat ini bergeser mengikuti paradigma patient-oriented. Meningkatnya jumlah pasien lanjut usia (lansia) dengan penyakit kronis membuat apoteker perlu mengembangkan upaya edukatif dan kolaboratif berbasis komunitas seperti home care. Klien home care yang mendapatkan banyak obat untuk penyakit kronis dari dokter dan apotek sering mengalami Drug Related Problems (DRP) serta dianggap mendapatkan sedikit supervisi atau bahkan tidak mendapatkannya sama sekali di rumahnya. Tujuan artikel review ini adalah untuk membahas aktivitas supervisi apoteker pada pelayanan kefarmasian untuk pasien lansia dalam konteks home care yang dapat mengungkapkan dan meningkatkan kepatuhan terapi. Penelitian yang memenuhi kriteria inklusi diambil dari basis data jurnal Pubmed, Science Direct, dan Google Scholar. Hasil penelusuran pustaka dari 16 artikel menunjukkan bahwa aktivitas supervisi terhadap terapi obat merupakan elemen pelayanan kefarmasian home care. Supervisi penggunaan obat oleh apoteker kepada pasien lansia yang mengalami penyakit kronis terbukti dapat meningkatkan kepatuhan apabila dilaksanakan secara inovatif dalam konteks home care. Model pelayanan yang terintegrasi dan berbasis komunitas seperti pelayanan di klinik atau rawat jalan di rumah sakit memberikan kesempatan kepada apoteker untuk berkolaborasi dengan tenaga kesehatan lainnya dalam rangka meningkatkan kepatuhan. Aktivitas supervisi meliputi rekonsiliasi obat, identifikasi dan manajemen masalah terkait obat, monitoring beberapa parameter klinis, penyesuaian rejimen dan dosis terapi, edukasi serta koordinasi pelayanan dengan tenaga kesehatan lainnya. Supervisi terapi obat dalam home care terbukti mampu mengungkap lebih banyak DRP dan angka ketidakpatuhan sekaligus memberikan solusinya. Kepatuhan dapat ditingkatkan dengan upaya-upaya inovatif untuk mendesain perangkat pendukung yang sesuai dengan kebutuhan pasien dan memudahkan apoteker dalam mentransfer pelayanannya.
\end{abstract}

Kata kunci: Apoteker, home care, kepatuhan, lanjut usia, penyakit kronis, supervisi

\section{Pharmacist Home Care Innovation through Supervision of Geriatric Drug Use to Improve Adherence with Chronic Disease Therapy}

\begin{abstract}
There is currently a shift in the pharmaceutical care provided in Indonesia towards the patient-oriented paradigm, alongside the increasing number of elderly with chronic diseases. Therefore, it is important to develop pharmacist activities towards drug therapy management, through community-based education and collaboration, including home care service. This provision by doctors and pharmacies to clients with drugs for chronic diseases often lead to Drug Related Problems (DRP), and are considered to encourage little or no supervision. The purpose of this review, therefore, is to discuss the pharmacist's supervision activities for elderly patients, in the context of home care, relevant to identify and improve therapy adherence. Furthermore, studies evaluated to have met the inclusion criteria were collected from journal databases, including Pubmed, Science Direct and Google Scholar. A total of sixteen articles showed supervision activities on drug therapy to be the element of pharmaceutical home care services. Hence, improved levels have been implicated in increased adherence, following an innovative implementation in the context of home care. Moreover, integrated and community-based service models, comprising services in clinics or outpatients in hospitals provide opportunities for pharmacists to collaborate with other health workers, and consequently promote adherence. The possible supervision activities include medication reconciliation; DRP identification and management; clinical parameters monitoring; adjusting therapy regimens and doses; education; and coordination of services with other health workers. These approaches have been proven to increase the average DRP per patient, and the non-adherence rate while providing a solution. However, adherence is possibly enhanced by design tools appropriate to the individual needs, and capable of facilitating the transfer of pharmacists' services.
\end{abstract}

Keywords: adherence, chronic disease, elderly, home care, pharmacist, supervision

Korespondensi: Prof. Dr. apt. Djoko Wahyono, SU., Program Pascasarjana Fakultas Farmasi, Universitas Gadjah Mada, Yogyakarta, D.I. Yogyakarta 55281, Indonesia, email: djokowahyono@ugm.ac.id

Naskah diterima: 21 Juni 2019, Diterima untuk diterbitkan: 5 November 2019, Diterbitkan: 29 Juni 2020 


\section{Pendahuluan}

Pharmaceutical care atau pelayanan kefarmasian, khususnya yang terkait farmasi klinik saat ini memiliki sebuah paradigma baru. Pergeseran paradigma ini membuat apoteker perlu memiliki kemampuan praktik, seperti edukasi, untuk diterapkan dalam mengelola terapi pasien dan menjadi bagian dari tim..$^{1-5}$ Negara berkembang seperti Thailand maupun negara maju seperti Amerika Serikat telah memposisikan apoteker sebagai bagian dari tim multidisipliner yang mampu berperan dalam pencegahan maupun penatalaksanaan penyakit kronis. ${ }^{6-8}$ Berdasarkan contoh praktik farmasi klinik tersebut, maka tergambar dengan jelas pengertian filosofi pharmaceutical care yang ditransformasikan menjadi aktivitas berbasis pelayanan. Aktivitas yang bersifat edukatif, preventif dan kolaboratif dalam praktik farmasi klinik dengan perubahan paradigma tersebut mengarah kepada patient-oriented. ${ }^{9}$

Pelayanan kefarmasian di Indonesia, sebagaimana di negara lain, bergeser pada cara pandang patient-oriented. Pelayanan apoteker yang dilaksanakan di fasilitas kesehatan primer maupun di setting lain untuk pasien penyakit kronis bergerak mengikuti model pelayanan kesehatan berbasis komunitas. ${ }^{2,5,10,11}$ Namun, hal ini mengakibatkan apoteker juga perlu dilengkapi keterampilan untuk individualisasi terapi, terutama untuk kelompok pasien tertentu seperti lanjut usia (lansia). ${ }^{12,13}$ Seiring dengan kompleksitas terapi obat pada satu dasawarsa terakhir, apoteker dituntut untuk berperan sebagai anggota pemberi pelayanan kesehatan yang dapat mengoptimalkan terapi obat. ${ }^{14}$ Pengembangan peran ini membuat mereka berkolaborasi dengan dokter maupun perawat dalam menyikapi perubahan orientasi pelayanan pasien tersebut. ${ }^{1,15-18}$

Home care apoteker merupakan bentuk pelayanan kefarmasian di rumah tempat tinggal pasien yang diberikan untuk pasien tertentu seperti lansia maupun pasien penyakit kronis. Di beberapa negara seperti Canada, Spanyol, Amerika Serikat, Inggris, Australia, Belanda, Denmark, Jordania, Singapura, dan India, penelitian-penelitian tentang pelayanan kefarmasian yang bertempat di tempat tinggal pasien biasanya berlangsung di rumah pasien, panti (care home, residential home) atau rumah perawatan lansia (home nursing). Berbagai hasil penelitian berupa original research yang menyatakan bentuk-bentuk intervensi kepada pasien menunjukkan bahwa home care oleh apoteker memberikan hasil yang bermanfaat seperti peningkatan kepatuhan penggunaan obat, diet, aktivitas fisik serta perbaikan luaran klinis seperti tekanan darah untuk penyakit kronis $^{19,20}$ hipertensi maupun Diabetes Melitus (DM) tipe 2.21,22 Hasil penelitian-penelitian tersebut memperlihatkan perlunya apoteker untuk melakukan kunjungan langsung ke rumah pasien.

Kunjungan apoteker sebagai salah satu bentuk intervensi multifaktorial yang memuat sebuah aktivitas supervisi telah terbukti dapat meningkatkan kepatuhan penggunaan obat. ${ }^{23}$ Namun, bentuk pelayanan kunjungan apoteker ini masih jarang dilakukan oleh apoteker di Indonesia. Meskipun belum ada peraturan di Indonesia yang secara khusus mengatur tentang home care, berbagai peraturan dan kebijakan yang dalam bagiannya memuat home care telah menyebutkan bahwa lansia dan pasien yang mengalami penyakit kronis beserta penggunaan obat-obatnya merupakan prioritas dari sasaran pelayanan. ${ }^{24-27}$ Namun, kebutuhan supervisi terhadap obat untuk penyakit kronis lansia di rumahnya belum dapat terpenuhi. ${ }^{28}$ Seiring dengan beragamnya penelitian yang mengkaji aktivitas supervisi sebagai bagian dari pelayanan kefarmasian yang dapat dilakukan dalam konteks home care dari berbagai negara, ${ }^{29}$ apoteker di Indonesia perlu mengetahui rincian kegiatan tersebut agar dapat diterapkan sesuai dengan keterampilan klinis yang dimiliki.

Artikel review ini bertujuan membahas 
aktivitas supervisi apoteker pada pelayanan kefarmasian untuk pasien lansia dalam konteks home care yang dapat mengungkapkan dan meningkatkan kepatuhan terapi. Aspek-aspek yang dibahas antara lain model intervensi, aktivitas supervisi pada pelayanan kefarmasian oleh apoteker, hasil/outcome beserta tool atau perangkatnya yang berpotensi meningkatkan kepatuhan.

\section{Metode}

Penulisan review ini disusun berdasarkan penelitian-penelitian yang terkait dengan dasar-dasar supervisi dalam aktivitas apoteker. Penelitian-penelitian tersebut diambil secara purposive sampling dari basis data Pubmed, Science Direct dan Google Scholar. Penyakit yang dibahas meliputi hipertensi, DM tipe 2 dan penyakit-penyakit kronis yang lain seperti Coronary Artery Disease (CAD), Congestive Heart Failure (CHF), Penyakit Paru Obstruksi Kronis (PPOK), infark miokard, aritmia, stroke, hiperlipidemia, penyakit ginjal kronis, epilepsi, serta osteoarthritis. Supervisi yang dimaksud dalam artikel ini adalah supervisi terapi obat kepada pasien sesuai dengan konsep pharmaceutical care.

Kriteria inklusi disesuaikan dengan tujuan artikel review ini sehingga kriteria artikel penelitian yang ditinjau berupa laporan atau hasil penelitian yang menyatakan praktikpraktik inovatif melalui aktivitas supervisi sebagai bentuk intervensi apoteker kepada pasien lansia dalam konteks home care. Artikel hasil penelitian maupun laporan yang memuat intervensi kepada pasien tersebut dipilih dengan beberapa kriteria inklusi yang lain yaitu penerbitan artikel pada rentang tahun 2009-2018, penelitian melibatkan pelayanan kefarmasian oleh apoteker, dilaksanakan di rumah pasien/home atau di rumah perawatan/ care home atau sebagai rangkaian dari pelayanan rumah sakit, klinik maupun apotek yang berkaitan dengan penggunaan obat di rumah pasien, melibatkan pasien lansia yang mengalami penyakit kronis, dapat diakses teks lengkapnya dan berbahasa Inggris.

Hasil-hasil penelitian yang ingin dirinci merupakan contoh-contoh praktik apoteker dengan model pelayanan atau tipe intervensi dalam konteks home care serta dilakukan secara kolaboratif. Kolaborasi antara apoteker dengan tenaga kesehatan atau pihak lain yang memberikan pelayanan terkait dengan obat memunculkan inovasi-inovasi yang tercermin pada kegiatan supervisinya. Kolaborasi tersebut dapat diwujudkan dalam model tim ataupun tipe intervensi lainnya yang memungkinkan adanya hubungan timbal balik secara sinergis antara apoteker dengan pihak lain dan adanya komunikasi saat memberi pelayanan kepada pasien.

Kriteria eksklusi yang pertama adalah peran apoteker yang tidak jelas dalam tipe intervensi yang dilakukan. Kriteria eksklusi selanjutnya adalah artikel penelitian yang tidak menjelaskan dengan rinci tentang aspek kolaborasi antara apoteker dengan pihak lain yang memberikan pelayanan dalam supervisi penggunaan obat pasien, artikel penelitian dengan metode survei yang mengungkapkan aktivitas home care oleh apoteker, artikel penelitian dengan subjek pasien lansia yang diagnosisnya baru merupakan faktor risiko penyakit kronis, dan artikel penelitian dengan setting pelayanan kefarmasian meliputi dua tempat dalam satu penelitian, yaitu rumah pasien serta nursing home.

Kata kunci yang digunakan pada proses pencarian pustaka adalah pharmacist, home care, intervention, elderly, dan supervision. Kombinasi kata kunci yang diterapkan di Pubmed adalah dengan "pharmacists" AND "home care" [MeSH Terms] AND "elderly" [MeSH Terms]; di Google Scholar dengan "pharmacist" AND "home care intervention" AND "elderly" AND "supervision"; dan di Science Direct dengan "pharmacist" AND "home care". Proses penelusuran pustaka awal 
mengidentifikasi 257 artikel, tetapi sebanyak 235 artikel dikeluarkan karena tidak memuat peran apoteker yang jelas, tidak dapat diakses teks lengkapnya, dan tidak berbahasa Inggris. Proses seleksi ini menghasilkan 22 artikel penelitian yang sesuai dengan kriteria inklusi dan setelah dilakukan skrining berdasarkan kriteria eksklusi berikutnya, diperoleh 16 artikel utama. Dokumen peraturan pemerintah dan artikel hasil penelitian lainnya merupakan literatur yang digunakan untuk mendukung penjelasan dalam pembahasan. Analisis yang dilakukan dalam artikel review ini dilakukan secara deskriptif. Rangkaian meta analisis yang juga menyertai sistematik review tidak memungkinkan untuk dilakukan disebabkan metode dan outcome yang sangat heterogen.

\section{Hasil}

Artikel review ini dirancang untuk dapat mengungkapkan aktivitas-aktivitas supervisi yang dilaksanakan oleh apoteker berdasarkan hasil-hasil studi yang telah dimuat dalam artikel terpilih. Langkah-langkah proses seleksi artikel pada review ini disajikan pada Gambar 1. Sebagaimana yang telah ditunjukkan pada Gambar 1, pencarian telah mengidentifikasi 257 artikel dengan sumber dan jumlah artikel yaitu: Pubmed (69 artikel), Science Direct (142 artikel), dan Google Scholar (46 artikel). Pemilihan artikel hasil-hasil penelitian sesuai tujuan penulisan pada mulanya menghasilkan 22 artikel sesuai dengan kriteria inklusi. Enam artikel kemudian dikeluarkan dengan kriteria eksklusi yang ditetapkan. Rincian dari keenam artikel yang dikeluarkan yaitu 1 artikel penelitian tidak menjelaskan dengan rinci aspek kolaborasi antara apoteker dengan pemberi pelayanan lainnya dalam supervisi penggunaan obat pasien, 3 artikel dengan metode penelitian survei, 1 artikel penelitian dengan subjek pasien lansia yang diagnosisnya merupakan faktor risiko penyakit kronis, dan 1 artikel penelitian menyebutkan setting pelayanan kefarmasian di 2 tempat, yaitu rumah pasien dan nursing home. Berdasarkan seleksi tersebut, diperoleh total 16 artikel yang sesuai dengan tujuan penulisan. Artikelartikel hasil penelitian tersebut kemudian ditinjau berdasarkan nama peneliti dan tahun publikasi, model atau tipe intervensi yang dapat mengungkapkan aspek inovasi dan kolaborasi, rincian aktivitas supervisi serta berbagai outcome yang ada. Secara rinci, aktivitas supervisi yang mendasari pelayanan kefarmasian dalam konteks home care oleh apoteker dapat dilihat pada Tabel 1.

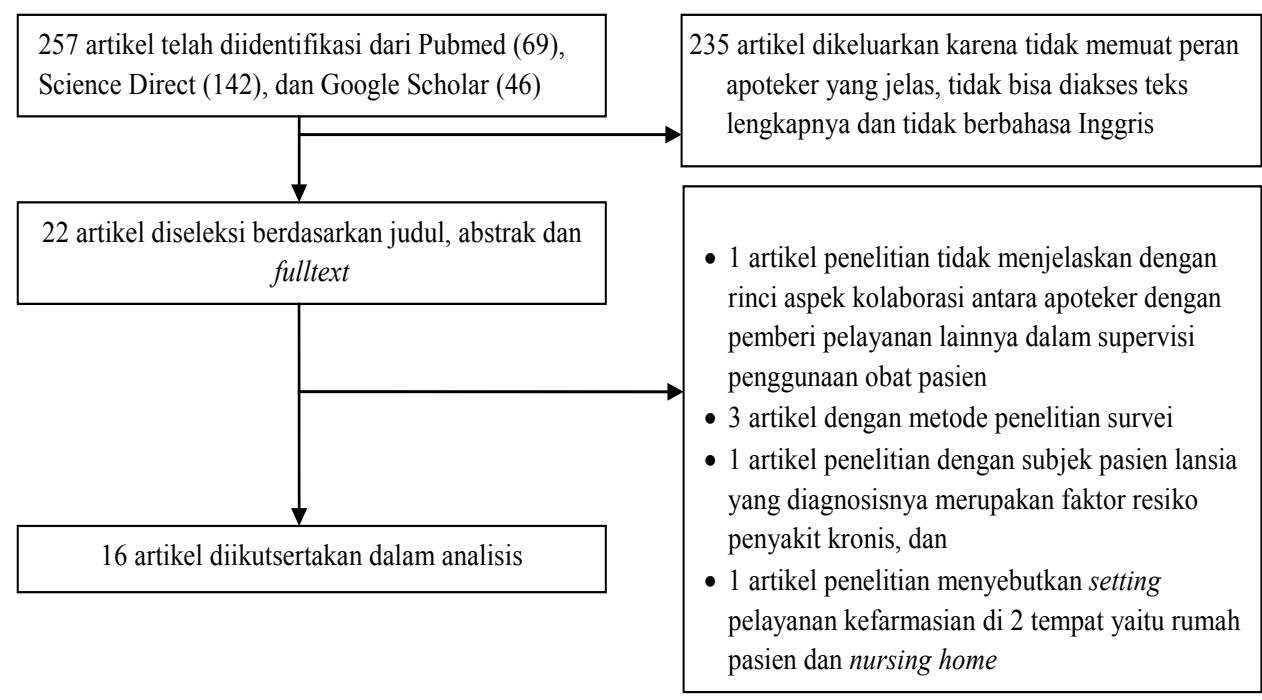

Gambar 1 Diagram PRISMA dalam Pemilihan Artikel 


\section{Tabel 1 Aktivitas Supervisi oleh Apoteker}

\begin{tabular}{|c|c|c|c|c|}
\hline Peneliti, Tahun & $\begin{array}{l}\text { Negara, } \\
\text { Jumlah } \\
\text { Pasien }\end{array}$ & $\begin{array}{l}\text { Model /Tipe } \\
\text { Intervensi }\end{array}$ & Aktivitas Supervisi & Outcome dan Nilai Statistikanya \\
\hline Hogg, et al. $(2009)^{30}$ & Canada, 241 & $\begin{array}{l}\text { Pelayanan } \\
\text { antisipatif dalam } \\
\text { tim preventif }\end{array}$ & $\begin{array}{l}\text { 1. Review terhadap } \\
\text { manajemen pengobatan } \\
\text { 2. Identifikasi Drug } \\
\text { Related Problem (DRP) } \\
\text { 3. Penyelesaian DRP }\end{array}$ & $\begin{array}{l}\text { 1. Outcome primer: Nilai kualitas pelayanan untuk manajemen } \\
\text { penyakit kronis meningkat secara signifikan } 9,2 \%(\mathrm{p}<0,001) \\
\text { terutama untuk manajemen terapi penyakit } \mathrm{DM} \\
\text { 2. Outcome sekunder: } \\
\text { Kepatuhan meningkat secara signifikan sebesar } 16,5 \% \\
\text { ( }<0,001) \text { dengan adanya pelayanan preventif } \\
\text { b. HbA1c kelompok intervensi mengalami penurunan sedangkan } \\
\text { kelompok kontrol mengalami peningkatan, tetapi tidak } \\
\text { bermakna secara statistik ( } \mathrm{p}=0,19) \\
\text { c. Tekanan darah kedua kelompok mengalami penurunan tetapi } \\
\text { tidak berbeda signifikan ( } \mathrm{p}=0,70) \\
\text { d. Kualitas hidup kedua kelompok tidak berbeda signifikan } \\
\text { berdasarkan kuesioner Short Form/SF-36 (komponen fisik } \\
\text { memiliki nilai } \mathrm{p}=0,18 \text {; komponen mental memiliki nilai } \\
\mathrm{p}=0,44) \text { dan Health Related Quality of Life (penilaian } \\
\text { mandiri kesehatan yang buruk atau baik memiliki nilai } \\
\mathrm{p}=0,98 \text {; jumlah hari yang tidak sehat dalam } 30 \text { hari terakhir } \\
\text { memiliki nilai } \mathrm{p}=0,39) \\
\text { e. Aktivitas keseharian kedua kelompok tidak berbeda signifikan } \\
\text { ( } \mathrm{p}=0,50) \\
\text { f. Kunjungan ke rumah sakit untuk rawat inap kedua kelompok } \\
\text { tidak berbeda signifikan ( } \mathrm{p}=0,48) \\
\text { g. Kunjungan ke Instalasi Gawat Darurat (IGD) kedua kelompok } \\
\text { tidak berbeda signifikan ( } \mathrm{p}=0,67)\end{array}$ \\
\hline Setter, et al. (2009) $)^{31}$ & $\begin{array}{l}\text { Amerika } \\
\text { Serikat, } 220\end{array}$ & $\begin{array}{l}\text { Intervensi } \\
\text { apoteker dan } \\
\text { perawat kepada } \\
\text { pasien yang } \\
\text { berada pada masa } \\
\text { transisi sepulang } \\
\text { dari rumah sakit } \\
\text { ke rumah pasien }\end{array}$ & $\begin{array}{l}\text { 1. Rekonsiliasi obat } \\
\text { 2. Penilaian status } \\
\text { kesehatan melalui } \\
\text { wawancara di rumah } \\
\text { 3. Dokumentasi } \\
\text { ketidaksesuaian obat } \\
\text { 4. Menyampaikan memo } \\
\text { tentang ketidaksesuaian } \\
\text { obat kepada perawat, } \\
\text { dokter, pasien atau } \\
\text { keluarganya } \\
\text { 5. Memulai konsultasi } \\
\text { dengan perawat untuk } \\
\text { menyelesaikan masalah } \\
\text { ketidaksesuaian obat }\end{array}$ & $\begin{array}{l}\text { 1. Outcome primer: Persentase ketidaksesuaian obat yang } \\
\text { dapat diselesaikan pada kelompok intervensi mencapai } 67,0 \% \text {, } \\
\text { sedangkan pada kelompok kontrol sebesar } 54,6 \% \text {. } \\
\text { Rata-rata tingkat penyelesaian ketidaksesuaian obat pada } \\
\text { kelompok intervensi }(0,7 \pm 0,4) \text { lebih tinggi dibanding kelompok } \\
\text { kontrol }(0,6 \pm 0,4)(\mathrm{p}<0,001) \\
\text { 2. Outcome sekunder pada kelompok kontrol lebih besar dibanding } \\
\text { kelompok intervensi: } \\
\text { a. Jumlah kunjungan dokter yang direncanakan }(3,5 \pm 2,7 \text { vs } \\
2,9 \pm 1,5) \\
\text { b. Kunjungan dokter karena kedaruratan }(0,4 \pm 1,0 \text { vs } 0,2 \pm 0,6) \\
\text { c. Berulangnya rawat inap }(1,1 \pm 4,2 \text { vs } 0,4 \pm 1,2)\end{array}$ \\
\hline
\end{tabular}


Tabel 1 (Lanjutan) Aktivitas Supervisi oleh Apoteker

\begin{tabular}{|c|c|c|c|c|}
\hline Peneliti, Tahun & $\begin{array}{l}\text { Negara, } \\
\text { Jumlah } \\
\text { Pasien }\end{array}$ & $\begin{array}{l}\text { Model /Tipe } \\
\text { Intervensi }\end{array}$ & Aktivitas Supervisi & Outcome dan Nilai Statistikanya \\
\hline Choe, et al. $(2012)^{36}$ & $\begin{array}{l}\text { Amerika } \\
\text { Serikat, } 949\end{array}$ & $\begin{array}{l}\text { Patient-Centered } \\
\text { Medical Home } \\
(\mathrm{PCMH})\end{array}$ & $\begin{array}{l}\text { 1. Rekonsiliasi obat } \\
\text { 2. Inisiasi pengobatan } \\
\text { 3. Penyesuaian dosis } \\
\text { 4. Penilaian kepatuhan pasien } \\
\text { 5. Self-management dan penetapan } \\
\text { tujuan terapi } \\
\text { 6. Edukasi tentang penyakit kronis } \\
\text { dan obatnya } \\
\text { 7. Beberapa penilaian fisik } \\
\text { 8. Pemesanan untuk kelengkapan tes } \\
\text { diagnostik dan alat kesehatan } \\
\text { 9. Rujukan kepada tenaga kesehatan } \\
\text { lainnya }\end{array}$ & $\begin{array}{l}\text { 1. Perubahan obat pada setiap kunjungan terjadi pada } \\
50 \% \text { tempat pelayanan kesehatan, khususnya untuk } \\
\text { pasien diabetes } \\
\text { 2. Parameter klinik seperti penurunan } \mathrm{HbA} 1 \mathrm{c} 0,9 \% \\
\text { untuk pasien dengan baseline } \mathrm{HbA} 1 \mathrm{c}>7 \% \text { dan } \\
\text { penurunan HbAlc } 1,8 \% \text { untuk pasien dengan } \\
\text { baseline } \mathrm{HbA} 1 \mathrm{c}>9 \%\end{array}$ \\
\hline Elliot, et al. $(2012)^{41}$ & Australia, 80 & $\begin{array}{l}\text { Medication review di } \\
\text { rumah yang dipimpin } \\
\text { oleh apoteker }\end{array}$ & $\begin{array}{l}\text { 1. Melakukan penelusuran riwayat } \\
\text { penggunaan obat } \\
\text { 2. Melakukan review terhadap obat } \\
\text { secara komprehensif }\end{array}$ & $\begin{array}{l}\text { 1. Proporsi pasien yang menerima kunjungan apoteker } \\
\text { ke rumah dalam } 28 \text { hari melalui metode intervensi } \\
(90,0 \%) \text { lebih banyak dibandingkan yang melalui } \\
\text { metode pelayanan biasa }(17,5 \%)(\mathrm{p}<0,0001) \\
\text { 2. Jumlah masalah terkait obat yang teridentifikasi } \\
\text { melalui intervensi kunjungan apoteker lebih banyak } \\
\text { (164) dibandingkan dengan metode pelayanan } \\
\text { biasa (21) } \\
\text { 3. Semua pendapat pasien, dokter, dan klinisi tentang } \\
\text { aktivitas apoteker menyatakan bahwa kegiatan } \\
\text { tersebut sangat bermanfaat }\end{array}$ \\
\hline $\begin{array}{l}\text { Leendertse, et al. } \\
(2013)^{38}\end{array}$ & Belanda, 674 & $\begin{array}{l}\text { Intervensi pelayanan } \\
\text { kefarmasian }\end{array}$ & $\begin{array}{l}\text { 1. Anamnesis/wawancara terhadap } \\
\text { pasien yang meliputi riwayat } \\
\text { pengobatan pasien } \\
\text { 2. Review farmakoterapi yang } \\
\text { meliputi identifikasi DRP dan } \\
\text { manajemen DRP }\end{array}$ & $\begin{array}{l}\text { 1. Outcome primer: } \\
\text { Frekuensi kunjungan ke rumah sakit untuk rawat } \\
\text { inap yang terkait dengan penggunaan obat pada } \\
\text { kelompok intervensi sebanyak } 6(1,6 \%) \text { atau lebih } \\
\text { sedikit dibandingkan dengan kelompok kontrol } \\
\text { yaitu } 10(3,2 \%) \\
\text { 2. Outcome sekunder semuanya tidak menunjukkan } \\
\text { perbedaan yang signifikan (p>0,05) yang meliputi: } \\
\text { a. Mortalitas } \\
\text { b. Kualitas hidup } \\
\text { c. Adverse Drug Events }\end{array}$ \\
\hline
\end{tabular}


Tabel 1 (Lanjutan) Aktivitas Supervisi oleh Apoteker

\begin{tabular}{|c|c|c|c|c|}
\hline Peneliti, Tahun & $\begin{array}{c}\text { Negara, } \\
\text { Jumlah } \\
\text { Pasien }\end{array}$ & $\begin{array}{l}\text { Model /Tipe } \\
\text { Intervensi }\end{array}$ & Aktivitas Supervisi & Outcome dan Nilai Statistikanya \\
\hline Olesen, et al. $(2013)^{34}$ & Denmark, 630 & Pharmaceutical care & $\begin{array}{l}\text { 1. Memeriksa daftar obat yang } \\
\text { mungkin menimbulkan efek } \\
\text { samping } \\
\text { 2. Memeriksa interaksi obat } \\
\text { 3. Memeriksa cara pemberian obat } \\
\text { 4. Mengupayakan penyederhanaan } \\
\text { rejimen } \\
\text { 5. Memberikan informasi obat } \\
\text { 6. Menangani leaflet informasi obat } \\
\text { 7. Memberikan motivasi untuk } \\
\text { kepatuhan pasien }\end{array}$ & $\begin{array}{l}\text { 1. Kepatuhan penggunaan obat pada pasien yang } \\
\text { memperoleh pelayanan ( } 11 \% \text { ) dan pada kelompok } \\
\text { kontrol }(10 \%) \text { tidak menunjukkan perbedaan yang } \\
\text { signifikan (odds ratio } 1,14 ; 95 \% \text { confidence } \\
\text { interval } 0,65-2,00) \\
\text { 2. Kunjungan ke rumah sakit untuk rawat inap juga } \\
\text { tidak berbeda signifikan ( } 30 \% \text { vs } 28 \% \text {; odds ratio } \\
\text { 1,14; } 95 \% \text { confidence interval } 0,78-1,67) \text {. } \\
\text { 3. Mortalitas juga tidak berbeda signifikan }(7,5 \% \text { vs } 5 \% \text {; } \\
\text { Hazard ratio } 1,14 ; 95 \% \text { confidence interval } \\
0,71-2,82)\end{array}$ \\
\hline Basheti, et al. $(2013)^{39}$ & Jordania, 167 & $\begin{array}{l}\text { Pelayanan medication } \\
\text { review di rumah }\end{array}$ & $\begin{array}{l}\text { 1. Identifikasi DRP } \\
\text { 2. Wawancara tentang manfaat } \\
\text { pelayanan medication review di } \\
\text { rumah }\end{array}$ & $\begin{array}{l}\text { 1. Prevalensi DRP yang teridentifikasi } 7,4 \pm 2,8 \text { per } \\
\text { pasien. Secara keseluruhan, ada } 7 \text { kelompok DRP } \\
\text { dengan rincian: } 34,7 \% \text { pasien mendapatkan obat } \\
\text { yang tidak perlu; } 68,3 \% \text { kondisi yang tidak diterapi } \\
\text { dan } 74,9 \% \text { mendapatkan terapi obat yang tidak } \\
\text { efektif; } 50,3 \% \text { mendapatkan dosis yang tidak } \\
\text { tepat; } 24 \% \text { mengalami efek samping obat; } 10,2 \% \\
\text { mengalami interaksi obat dan } 46,1 \% \text { mengalami } \\
\text { masalah ketidakpatuhan dalam penggunaan obat } \\
\text { 2. Keterkaitan antara DRP dengan penyakit maupun } \\
\text { antara DRP dengan jumlah obat, keduanya } \\
\text { memiliki korelasi yang signifikan, yaitu ( } \mathrm{r}=0,311 \text {, } \\
\mathrm{p}=0,003 \text { ) dan ( } \mathrm{r}=0,443, \mathrm{p}<0,001) \text { masing-masing } \\
\text { 3. Pasien dapat menerima terhadap pelayanan } \\
\text { medication review di rumah dengan baik }\end{array}$ \\
\hline $\begin{array}{l}\text { Collier dan Baker } \\
(2013)^{32}\end{array}$ & $\begin{array}{l}\text { Amerika } \\
\text { Serikat, } 85\end{array}$ & $\begin{array}{l}\text { Pelayanan apoteker } \\
\text { di klinik rawat rawat } \\
\text { jalan diabetes khusus } \\
\text { untuk veteran }\end{array}$ & $\begin{array}{l}\text { 1. Penerapan standar protokol dan } \\
\text { prosedur terapi insulin } \\
\text { 2. Penyesuaian dosis antidabetes } \\
\text { oral dan insulin berdasarkan data } \\
\text { pemantauan gula darah mandiri } \\
\text { 3. Monitoring HbAlc } \\
\text { 4. Edukasi untuk mencegah } \\
\text { hipoglikemia }\end{array}$ & $\begin{array}{l}\text { HbA1c turun secara signifikan lebih dari } 1 \% \\
\text { (dari } 9,12 \% \pm 1,41 \% \text { menjadi } 7,94 \% \pm 1,18 \% \text { ) dalam } \\
\text { kurun waktu } 3 \text { bulan. Penurunan juga terjadi secara } \\
\text { signifikan setelah } 6 \text { bulan. Uji t berpasangan juga } \\
\text { menunjukkan penurunan HbA1c yang signifikan } \\
\text { selama } 3 \text { bulan dan } 6 \text { bulan. }\end{array}$ \\
\hline
\end{tabular}


Tabel 1 (Lanjutan) Aktivitas Supervisi oleh Apoteker

\begin{tabular}{|c|c|c|c|c|}
\hline Peneliti, Tahun & $\begin{array}{l}\text { Negara, } \\
\text { Jumlah } \\
\text { Pasien }\end{array}$ & $\begin{array}{l}\text { Model /Tipe } \\
\text { Intervensi }\end{array}$ & Aktivitas Supervisi & Outcome dan Nilai Statistikanya \\
\hline $\begin{array}{l}\text { Rojas-Fernandez, et al. } \\
(2014)^{3}\end{array}$ & Canada, 24 & $\begin{array}{l}\text { Pendekatan } \\
\text { farmakoterapi }\end{array}$ & $\begin{array}{l}\text { 1. Penilaian kesesuaian pengobatan } \\
\text { berdasarkan risiko kelemahan } \\
\text { pasien } \\
\text { 2. Penilaian obat yang dapat } \\
\text { merusak fungsi kognisi } \\
\text { 3. Penilaian kepatuhan dan } \\
\text { keterampilan dalam mengatur obat } \\
\text { 4. Pengendalian faktor risiko } \\
\text { vaskular } \\
\text { 5. Edukasi terkait dengan } \\
\text { pengobatan, penyakit, transisi } \\
\text { perawatan }\end{array}$ & $\begin{array}{l}\text { DRP yang teridentifikasi meliputi kondisi yang } \\
\text { tidak diterapi }(2,9 \%) \text {, dosis suboptimal }(18 \%) \text {, efek } \\
\text { samping obat aktual/potensial }(15 \%) \text { dan masalah } \\
\text { kepatuhan }(14 \%) \text { serta penggunaan obat tanpa } \\
\text { indikasi }(11 \%) \text {. Kontribusi apoteker berupa } 88 \\
\text { rekomendasi yang meliputi penghentian pengobatan } \\
(20 \%) \text {, memulai pengobatan baru }(19 \%) \text {, perubahan } \\
\text { dosis }(14 \%) \text { dan perubahan ke obat lain }(10 \%) \text {, } \\
\text { edukasi pasien atau caregiver }(8 \%) \text { dan dapat } \\
\text { meningkatkan kepatuhan }(10 \%)\end{array}$ \\
\hline Leiva, et al. $(2014)^{23}$ & Spanyol, 230 & $\begin{array}{l}\text { Intervensi } \\
\text { multifaktor }\end{array}$ & $\begin{array}{l}\text { 1. Wawancara untuk memberikan } \\
\text { motivasi } \\
\text { 2. Sistem pengingat dengan kotak } \\
\text { obat } \\
\text { 3. Dukungan keluarga } \\
\text { 4. Pengukuran tekanan darah dan } \\
\text { formulir untuk mengingat obat } \\
\text { antihipertensi } \\
\text { 5. Penyederhanaan regimen terapi }\end{array}$ & $\begin{array}{l}\text { 1. Pencapaian tekanan darah sistolik kelompok } \\
\text { intervensi }(151,3 \mathrm{mmHg}) \text { tidak berbeda signifikan } \\
\text { dengan kelompok kontrol }(153,7 \mathrm{mmHg}) \\
\text { 2. Pencapaian tekanan darah diastolik kelompok } \\
\text { intervensi }(83,4 \mathrm{mmHg}) \text { tidak berbeda signifikan } \\
\text { dengan kelompok kontrol }(83,6 \mathrm{mmHg}) \text {. } \\
\text { 3. Persentase pasien yang tekanan darahnya terkontrol } \\
\text { pada kelompok intervensi }(15,8 \%) \text { lebih tinggi } \\
\text { dibanding kelompok kontrol }(9,2 \%)\end{array}$ \\
\hline Porter, et al. $(2014)^{35}$ & $\begin{array}{l}\text { Amerika } \\
\text { Serikat, } 60\end{array}$ & $\begin{array}{l}\text { Penggunaan kotak } \\
\text { obat untuk mengatur } \\
\text { obat antihipertensi }\end{array}$ & $\begin{array}{l}\text { 1. Verifikasi obat berdasarkan rekam } \\
\text { medik } \\
\text { 2. Edukasi dan training kepada } \\
\text { pasien atau caregiver untuk } \\
\text { mengisi kotak obat }\end{array}$ & $\begin{array}{l}\text { Tekanan darah sistolik tidak berbeda signifikan, tetapi } \\
\text { semua pasien memiliki tingkat kepatuhan lebih dari } \\
\text { atau sama dengan } 80 \% \text { terhadap penggunaan obat } \\
\text { antihipertensi }\end{array}$ \\
\hline $\begin{array}{l}\text { Andreassen, et al. } \\
(2016)^{42}\end{array}$ & Inggris, 826 & $\begin{array}{l}\text { Penilaian keamanan } \\
\text { penggunaan obat }\end{array}$ & $\begin{array}{l}\text { 1. Penilaian terhadap obat yang } \\
\text { tidak sesuai } \\
\text { 2. Penghentian penggunaan obat } \\
\text { yang tidak sesuai }\end{array}$ & $\begin{array}{l}\text { Penggunaan obat yang tidak sesuai pada pasien DM } \\
\text { dialami oleh lebih dari } 90 \text { persen lansia dan masing- } \\
\text { masing pasien mengalami setidaknya } 1 \text { penggunaan } \\
\text { obat yang berpotensi tidak tepat. Peran apoteker } \\
\text { dicapai dengan mengurangi kejadian polifarmasi } \\
\text { dan efek samping obat sehingga dapat meningkatkan } \\
\text { kepatuhan terapi }\end{array}$ \\
\hline
\end{tabular}


Tabel 1 (Lanjutan) Aktivitas Supervisi oleh Apoteker

\begin{tabular}{|c|c|c|c|c|}
\hline Peneliti, Tahun & $\begin{array}{l}\text { Negara, } \\
\text { Jumlah } \\
\text { Pasien }\end{array}$ & $\begin{array}{l}\text { Model /Tipe } \\
\text { Intervensi }\end{array}$ & Aktivitas Supervisi & Outcome dan Nilai Statistikanya \\
\hline $\begin{array}{l}\text { Cheen, et al. } \\
(2016)^{40}\end{array}$ & $\begin{array}{l}\text { Singapura, } \\
499\end{array}$ & $\begin{array}{l}\text { Pelayanan medication } \\
\text { review di rumah }\end{array}$ & $\begin{array}{l}\text { 1. Melakukan review terhadap obat } \\
\text { secara komprehensif } \\
\text { 2. Manajemen penyakit } \\
\text { 3. Konseling obat } \\
\text { 4. Manajemen DRP } \\
\text { 5. Koordinasi pelayanan dengan } \\
\text { dokter }\end{array}$ & $\begin{array}{l}\text { 1. Outcome primer: } \\
\text { Kunjungan ke rumah sakit untuk rawat inap dalam } \\
\text { kurun waktu } 6 \text { bulan setelah pelayanan di rumah } \\
\text { mengalami penurunan sebanyak } 26 \% \text { pada kelompok } \\
\text { pasien yang mendapatkan medication review berbasis } \\
\text { home care } \\
\text { 2. Outcome sekunder: } \\
\text { a. Kunjungan ke instalasi gawat darurat berkurang } \\
\text { sebanyak } 20 \% \\
\text { b. Kunjungan rawat jalan meningkat sebanyak } 16 \% \\
\text { c. Mortalitas terjadi hanya pada kelompok intervensi }\end{array}$ \\
\hline Elliot, et al. $(2017)^{37}$ & Australia, 84 & $\begin{array}{l}\text { Medication review di } \\
\text { rumah yang dipimpin } \\
\text { oleh apoteker }\end{array}$ & $\begin{array}{l}\text { 1. Melakukan review terhadap obat } \\
\text { secara komprehensif } \\
\text { 2. Rekonsiliasi obat } \\
\text { 3. Koordinasi pelayanan dengan } \\
\text { geriatrician } \\
\text { 4. Memberikan laporan kepada } \\
\text { dokter dan apoteker di apotek } \\
\text { yang melayani obat pasien }\end{array}$ & $\begin{array}{l}\text { 1. Pasien yang mendapatkan medication review dari } \\
\text { apoteker mencapai } 85 \% \text { dari total } 95 \text { pasien. } \\
\text { Delapan puluh dua pasien memerlukan home visit } \\
\text { 2. Kejadian DRP berupa obat yang tidak tepat dialami } \\
\text { oleh } 22 \% \text { pasien. Empat puluh dua persen pasien } \\
\text { mengalami terapi dengan rejimen yang kompleks } \\
\text { sehingga dirujuk oleh perawat kepada apoteker } \\
\text { 3. Opini dari pasien, dokter dan klinisi terhadap } \\
\text { pelayanan medication review yang dilakukan oleh } \\
\text { apoteker berupa persetujuan atas adanya home visit } \\
\text { yang dilakukan oleh apoteker }\end{array}$ \\
\hline $\begin{array}{l}\text { Walus dan } \\
\text { Woloschuk }(2017)^{10}\end{array}$ & Canada, 184 & $\begin{array}{l}\text { Program percontohan } \\
\text { pelayanan home care } \\
\text { berbasis komunitas }\end{array}$ & $\begin{array}{l}\text { 1. Melakukan review terhadap obat } \\
\text { 2. Memberikan edukasi }\end{array}$ & $\begin{array}{l}\text { 1. Jumlah DRP yang teridentifikasi dan yang } \\
\text { terselesaikan sebanyak } 271 \\
\text { 2. Penerimaan staf home care terhadap rekomendasi } \\
\text { apoteker mencapai } 90,2 \% \\
\text { 3. Indikator kinerja farmasi klinik mencapai } 15 \text { Clinical } \\
\text { Pharmacy Key Performance Indicators (CPKPIs) }\end{array}$ \\
\hline $\begin{array}{l}\text { Biswas, et al. } \\
(2018)^{33}\end{array}$ & India, 75 & $\begin{array}{l}\text { Intervensi } \\
\text { farmakoterapi } \\
\text { berbasis komunitas }\end{array}$ & $\begin{array}{l}\text { 1. Konseling } \\
\text { 2. Monitoring } \\
\text { 3. Penjadwalan obat } \\
\text { 4. Edukasi }\end{array}$ & $\begin{array}{l}\text { 1. Pengetahuan pasien tentang obat terungkap sangat } \\
\text { terbatas } \\
\text { 2. Tingkat kepatuhan pasien yang mendapatkan } \\
\text { supervisi berbeda signifikan bila dibandingkan } \\
\text { dengan kelompok yang tidak mendapatkan supervisi } \\
(p<0,0001)\end{array}$ \\
\hline
\end{tabular}




\section{Pembahasan}

Berbagai upaya yang dilakukan apoteker dalam tim untuk mengungkapkan dan meningkatkan kepatuhan menghasilkan berbagai outcome, baik yang hasilnya berbeda signifikan maupun yang tidak berbeda signifikan. Empat studi memberikan penegasan bahwa peningkatan kepatuhan pasien yang signifikan diperoleh akibat dari upaya apoteker bersama dengan tim kesehatan untuk kelompok pasien yang diberikan intervensi dibandingkan dengan pasien yang tidak mendapatkan intervensi. ${ }^{30-33}$ Tiga studi yang lainnya menegaskan bahwa peningkatan kepatuhan yang diperoleh tidak signifikan. ${ }^{23,34,35}$ Delapan studi membahas upaya-upaya mengungkapkan ketidakpatuhan sebagai DRP. Apoteker selanjutnya berusaha mengatasi ketidakpatuhan tersebut sebagai bagian dari pelayanan home care., , $10,36-41^{-1}$ Satu studi berfokus pada kepatuhan dalam rangka menjalani penghentian pengobatan yang tidak sesuai pada lansia sehingga dapat mengurangi efek samping. ${ }^{42}$ Seluruh hasil studi tersebut dapat dilihat sebagai upayaupaya yang dilakukan untuk mengungkapkan dan meningkatkan kepatuhan pasien.

Artikel review tentang supervisi ini dapat digunakan sebagai acuan karena berisi contoh model pelayanan kefarmasian oleh apoteker yang hendak menerapkan home care dalam aktivitas pelayanannya. Secara garis besar, semua model home care dari total 16 artikel yang ditinjau merupakan pelayanan berbasis komunitas. ${ }^{3,10,23,30-42}$ Pada Tabel 1, ditunjukkan berbagai istilah model telah digunakan untuk menamai tipe intervensi home care berdasarkan sifat kolaboratif dan setting pelayanan serta teknik yang digunakan oleh apoteker untuk dapat berperan di dalamnya. Beberapa istilah yang terkait dengan model home care telah ditemukan dalam review ini seperti pelayanan antisipatif dalam tim preventif, ${ }^{30}$ intervensi pada masa transisi sepulang dari rumah sakit ke rumah pasien, ${ }^{31}$ supervisi dengan setting di instalasi rawat jalan rumah sakit veteran, ${ }^{32}$ serta intervensi farmakoterapi berbasis komunitas. ${ }^{10}$ Beberapa istilah model lainnya yang digunakan antara lain Patient Centered Medical Home (PCMH) ${ }^{36}$ home medication review, ${ }^{37,39-41}$ pharmaceutical care, ${ }^{3,33,34,38}$ intervensi multifaktor, ${ }^{23}$ sampai dengan istilah yang paling spesifik seperti intervensi penggunaan kotak obat ${ }^{35}$ dan penilaian keamanan penggunaan obat. ${ }^{42}$ Pengenalan terhadap model-model ini bermanfaat untuk merancang pelayanan kefarmasian home care yang diperlukan oleh apoteker.

Model home care oleh apoteker di berbagai negara sebagaimana yang diulas pada Tabel 1 mengintegrasikan dan merangkai pelayanan dari rumah sakit atau apotek, sampai ke rumah pasien. Setelah pasien sampai di rumahnya, aktivitas apoteker dalam melakukan supervisi dapat dilanjutkan dengan melalui home visit atau menggunakan media komunikasi lainnya dengan melihat basis data di tempat awal pelayanannya yang merupakan tempat praktik apoteker semula. Aktivitas seperti medication review yang meliputi rekonsiliasi obat, penelusuran riwayat penggunaan obat maupun identifikasi DRP juga dapat dilakukan melalui telepon, atau bahkan dengan melihat dokumen rekam medis dan resep. ${ }^{16,43}$ Proses supervisi dengan melihat kedua dokumen tersebut beserta lanjutannya dalam konteks rangkaian pelayanan home care sesuai dengan konsep medication surveillance yang meliputi pengecekan resep untuk menghindari interaksi obat maupun duplikasi obat, kontraindikasi, pengecekan terhadap kepatuhan dan pengecekan terhadap permasalahan yang terkait dengan dosis. ${ }^{9,44}$ Oleh karena itu, rangkaian pelayanan tersebut merupakan sistem yang berkelanjutan dengan adanya pengumpulan data secara sistematik, analisis dan interpretasi data beserta tindak lanjutnya.

Peningkatan kepatuhan dapat dicapai dengan salah satu model home care yang telah 
diterapkan dalam pelayanan kefarmasian. Pelayanan bersifat preventif dan antisipatif di level primer dengan keberadaan apoteker yang memberikan home care bersama dengan tim tenaga kesehatan dapat meningkatkan kepatuhan terapi, terutama untuk pasien DM. Apoteker berinovasi dengan menjadi konsultan bagi perawat yang sama-sama melaksanakan supervisi ketika melaksanakan home care. Dengan demikian, home care menjadi wahana penghantaran pelayanan secara eksklusif agar apoteker dapat memberikan manajemen DRP kepada pasien. ${ }^{30}$

Apoteker di Belanda dapat mengidentifikasi DRP rata-rata mencapai 2,8 per pasien melalui model medication surveillance. Namun, apabila identifikasi DRP dilakukan di rumah pasien, apoteker dapat melihat kenyataan yang lebih banyak melalui penggunaan obat secara langsung untuk menjamin penyelesaian DRP tersebut. Clinical pharmacist yang melakukan kunjungan ke rumah pasien di Jordania dapat mengidentifikasi rata-rata DRP per pasien mencapai 7,4 $\pm 2,8$ dan apoteker di Singapura mengidentifikasi 4,9 $\pm 3,4 .{ }^{39,40}$ Berdasarkan hasil tersebut, kunjungan ke rumah menunjukkan hasil rata-rata identifikasi DRP lebih banyak.

Penelitian di Jordania dapat menjadi salah satu contoh yang menjelaskan kemampuan home visit untuk mengungkapkan kepatuhan pasien ketika diteliti secara independen. Penelitian ini dirancang oleh 3 peneliti yang merupakan clinical pharmacist dan melibatkan 170 orang mahasiswa yang sedang menjalani magang di apotek. Pelayanan yang biasa secara umum (usual care) kepada pasien diberikan oleh apoteker penanggungjawab apotek tempat magang mahasiswa. Oleh karena itu, apoteker yang ada di apotek bukanlah clinical pharmacist yang menjadi peneliti dan apotek yang digunakan sebagai tempat magang tidak memiliki hubungan khusus dengan clinical pharmacist yang menjadi peneliti. Peneliti memberikan penjelasan kepada apoteker penanggungjawab apotek mengenai program ini dan apoteker memberikan persetujuannya dengan menandatangani informed consent. Lalu mahasiswa magang diberikan pelatihan sebelum terjun langsung dalam pengambilan data medication review sebagai bagian dari pelayanan home care di rumah pasien. Ketiga peneliti yang merupakan clinical pharmacist selanjutnya memberikan tindak lanjut pelayanan home care kepada pasien berdasarkan analisis data yang diperoleh. Berdasarkan penelitian tersebut, DRP yang teridentifikasi di rumah pasien mencapai 658 kejadian dan dikelompokkan menjadi 7 DRP. Ketujuh DRP tersebut adalah terapi obat yang tidak perlu, kondisi yang tidak diterapi, terapi yang tidak efektif, dosis yang tidak sesuai, efek samping obat, interaksi obat, dan ketidakpatuhan terhadap terapi obat. Ketidakpatuhan terhadap terapi obat yang terungkap secara keseluruhan mencapai $46,1 \%$ dan rata-rata ketidakpatuhan terhadap terapi farmakologi per pasien mencapai $1,5 \pm 0,50$ dengan kejadian terbanyak pada obat DM dan hipertensi. ${ }^{39}$

Contoh lain yang menjelaskan aktivitas supervisi apoteker untuk mengungkapkan ketidakpatuhan sebagai DRP yaitu penelitian yang dilakukan di Singapura. Penelitian ini merupakan evaluasi terhadap program pelayanan transisi untuk pasien yang baru keluar dari rumah sakit dan memiliki resiko tinggi untuk kembali masuk ke rumah sakit. Ketidakpatuhan terhadap obat sering terjadi pada kelompok pasien yang mendapatkan medication review berbasis home visit oleh apoteker. Apoteker berhasil mengungkap ratarata 5 DRP per pasien dengan kategori yang paling sering adalah ketidakpatuhan $(38,6 \%)$. Apoteker harus berusaha lebih keras untuk mengatasi masalah ketidakpatuhan pada lansia. Ketika berkunjung ke rumah, apoteker menyelesaikan DRP dan memberi konseling. Oleh karena itu, hambatan-hambatan yang sering terjadi pada masalah ketidakpatuhan dapat teridentifikasi dan kemudian diatasi 
secara bersama-sama oleh apoteker dan dokter. Komunikasi dengan dokter dijalin melalui surat tertulis dan melalui telepon. ${ }^{40}$

Home care yang diberikan untuk pasien dengan risiko tinggi ditujukan kepada pasien yang rentan mengalami masuk rumah sakit terkait dengan penggunaan obat, berusia 65 tahun atau lebih, mendapatkan 5 obat atau lebih untuk terapi penyakit kronis, memiliki satu obat yang selalu diulang dan pasien yang tidak patuh. ${ }^{38}$ Hal ini menunjukkan bahwa lansia mempunyai masalah yang kompleks sehingga perlu pendekatan pada perilaku. Apoteker memerlukan kesadaran yang tinggi akan pentingnya motivasi terhadap kepatuhan dengan cara memberikan motivasi ketika mengunjungi pasien di rumah. ${ }^{34}$ Apoteker juga dapat menggunakan teknik motivational interview dengan berdasarkan teori health belief model untuk menggali ketidakpatuhan. Penggalian terhadap kebutuhan pasien secara komprehensif bersama tim tenaga kesehatan lainnya terbukti dapat mengatasi DRP dan meningkatkan kepatuhan. ${ }^{37}$ Kerjasama yang baik ditunjukkan dengan adanya perawat merujuk pasien yang kurang patuh kepada apoteker sehingga dapat diberi edukasi untuk meningkatkan kepatuhan. ${ }^{10}$ Pasien lansia juga memerlukan komunikasi yang lancar dengan apoteker maupun tenaga kesehatan lainnya. Selain itu, pelayanan yang berkesinambungan juga memiliki pengaruh yang positif terhadap kualitas kesehatan lansia. ${ }^{33}$

Aktivitas supervisi muncul sebagai elemen pelayanan kefarmasian home care yang bisa dilaksanakan di rumah sakit, primary care maupun apotek. Bentuk aktivitas supervisi yang banyak disebutkan di dalam artikelartikel tersebut yakni rekonsiliasi obat, ${ }^{31,36,37}$ identifikasi dan manajemen DRP, 3,10,30,34,37-42 monitoring parameter-parameter klinis, ${ }^{23,32}$ penyesuaian rejimen dan dosis terapi, ${ }^{23,32-34,36}$ edukasi, ${ }^{3,10,23,32-36,40}$ serta koordinasi antara apoteker bersama pihak lainnya. ${ }^{23,31,36,37,40}$ Pengelompokan aktivitas supervisi dapat beragam sesuai tujuannya, dan perangkat atau tools yang diperlukan juga berbeda-beda seperti yang dapat dilihat pada Tabel 2.

Tabel 2 Aktivitas Supervisi beserta Perangkat dan Strategi untuk Mendorong Kepatuhan

\begin{tabular}{|c|c|c|c|}
\hline Tujuan & Intervensi & Aktivitas Supervisi & Perangkat dan strategi \\
\hline $\begin{array}{l}\text { Penilaian } \\
\text { kepatuhan }\end{array}$ & Medication review & $\begin{array}{l}\text { 1. Rekonsiliasi obat }{ }^{31-33} \\
\text { 2. Identifikasi dan manajemen } \\
\text { Drug Related Problems (DRP), } \\
\text { termasuk di dalamnya adalah } \\
\text { evaluasi yang cermat terhadap } \\
\text { efek samping yang dirasakan } \\
\text { dan interaksi obat }{ }^{3,10,30,33-36,39-41} \\
\text { 3. Monitoring tekanan darah, gula } \\
\text { darah dan HbA1 }{ }^{23,37}\end{array}$ & $\begin{array}{l}\text { 1. Formulir rekonsiliasi } \\
\text { 2. Pill count (observasi langsung) } \\
\text { 3. Kuesioner kepatuhan (Morisky } \\
\text { Medication Adherence Scalel } \\
\text { MMAS) } \\
\text { 4. Rekam medik elektronik }\end{array}$ \\
\hline \multirow[t]{3}{*}{$\begin{array}{l}\text { Meningkatkan } \\
\text { kepatuhan }\end{array}$} & $\begin{array}{l}\text { 1. Evaluasi } \\
\text { terhadap } \\
\text { kesesuaian } \\
\text { pengobatan }\end{array}$ & $\begin{array}{l}\text { Penyesuaian rejimen dan dosis } \\
\text { terapi }^{23,32,35,37,42}\end{array}$ & $\begin{array}{l}\text { 1. Formulir ketidaksesuaian obat } \\
\text { 2. Memo kepada perawat }\end{array}$ \\
\hline & 2. Edukasi & $\begin{array}{l}\text { 1. Edukasi tentang obat }{ }^{3,10,32,35,37,38,42} \\
\text { 2. Edukasi tentang penyakit }{ }^{3,32,37}\end{array}$ & $\begin{array}{l}\text { 1. Kuesioner tingkat pengetahuan } \\
\text { 2. Berbagai media edukasi dan } \\
\text { alat pengingat seperti penggunaan } \\
\text { leaflet, kalender pengingat, dos } \\
\text { set, kemasan blister, dan alarm } \\
\text { clock }\end{array}$ \\
\hline & $\begin{array}{l}\text { 3. Kolaborasi } \\
\text { pelayanan }\end{array}$ & $\begin{array}{l}\text { Diskusi terkait obat dan koordinasi } \\
\text { pelayanan dengan dokter, perawat, } \\
\text { dan keluarga } \\
\text { 23,31-33,40 }\end{array}$ & Formulir rujukan pelayanan \\
\hline
\end{tabular}


Pemahaman yang baru terhadap aktivitas supervisi akan menumbuhkan kesadaran apoteker terhadap perlunya menerapkan home care untuk lansia dan pasien yang mengalami penyakit kronis. Penerapan aktivitas supervisi secara inovatif dalam konteks home care dapat meningkatkan kepatuhan ${ }^{3,10,23,30-42}$ pasien lansia terhadap penggunaan obat untuk penyakit kronis dan dapat meningkatkan outcome terapi. Beberapa aktivitas supervisi apoteker di lower-middle-income economies country seperti India ${ }^{33}$ dan upper-middle economies country seperti Jordania ${ }^{39}$ dapat memberikan gambaran pelaksanaan praktik yang esensial kepada apoteker di Indonesia. Negara-negara lain yang termasuk ke dalam high-income economies seperti Canada, , $, 10,30$ Spanyol, ${ }^{23}$ Amerika Serikat, ${ }^{31,32,35,36}$ Inggris, ${ }^{42}$ Australia, ${ }^{37,41}$ Belanda, $^{38}$ Denmark $^{34}$ dan Singapura ${ }^{40}$ juga menjadi contoh ideal yang tidak kalah pentingnya untuk memperkaya wawasan apoteker di Indonesia terhadap pelayanan kefarmasian di negara maju.

Keterbatasan yang terdapat pada review ini adalah review ini sebagian besar meninjau aktivitas apoteker di negara-negara maju dan hanya sedikit mengungkapkan contoh aktivitas apoteker di negara berkembang. Oleh karena itu, perlu strategi dan pendekatan inovatif apabila hendak diterapkan di negara berkembang seperti Indonesia. Penerapan aktivitas supervisi yang diulas dalam review ini juga perlu memperhatikan perangkatperangkat yang hendak digunakan agar dapat diintegrasikan dalam pelaksanaan panduan home pharmacy care yang ada di Indonesia. Perangkat yang dimaksud adalah beberapa formulir atau strategi yang dapat digunakan secara teknis dalam pelaksanaan supervisi seperti kuesioner untuk mengukur tingkat kepatuhan maupun berbagai media edukasi tentang penyakit dan pengobatan. ${ }^{3,10,32-36,40}$ Kuesioner yang spesifik bagi masyarakat Indonesia perlu dikembangkan beserta perangkat-perangkat lain. Penggunaan media edukasi dan komunikasi perlu disesuaikan dengan kebutuhan pasien agar lebih sesuai diterapkan oleh apoteker.

\section{Simpulan}

Supervisi penggunaan obat oleh apoteker kepada pasien lansia yang mengalami penyakit kronis terbukti dapat meningkatkan kepatuhan apabila dilaksanakan secara inovatif dalam konteks home care. Model pelayanan di level primer yang bersifat preventif dan berbasis komunitas seperti pelayanan di klinik atau rawat jalan memberikan kesempatan kepada apoteker untuk mengembangkan edukasi kepada pasien dan melakukan kolaborasi dengan tenaga kesehatan yang lainnya dalam rangka meningkatkan kepatuhan. Apoteker dapat melakukan rekonsiliasi obat, identifikasi dan manajemen DRP, monitoring beberapa parameter klinis, penyesuaian rejimen dan dosis terapi, edukasi serta koordinasi pelayanan dengan tenaga kesehatan lainnya. Supervisi terapi obat dalam home care terbukti mampu mengungkap lebih banyak jumlah DRP ratarata per pasien dan angka ketidakpatuhan sekaligus memberikan solusinya. Kepatuhan dapat ditingkatkan dengan melakukan upayaupaya inovatif seperti membuat formulir rekonsiliasi obat, melakukan observasi langsung dalam rangka memantau kepatuhan, mendesain kuesioner kepatuhan, memulai penggunaan rekam medik elektronik, membuat formulir ketidaksesuaian obat, membuat memo untuk diberikan ke perawat, mendesain kuesioner tingkat pengetahuan, membuat formulir tentang rujukan pelayanan dari apoteker dan membuat berbagai media edukasi yang memiliki potensi untuk meningkatkan kepatuhan terapi pada penyakit kronis.

\section{Pendanaan}

Penulisan artikel review ini tidak didanai oleh sumber hibah manapun. 


\section{Konflik Kepentingan}

Seluruh penulis menyatakan tidak terdapat potensi konflik kepentingan dengan penelitian, kepenulisan (authorship), dan atau publikasi artikel ini.

\section{Daftar Pustaka}

1. Supper I, Catala O, Lustman M, Chemla C, Bourgueil Y, Letrilliart L. Interprofessional collaboration in primary health care: A review of facilitators and barriers perceived by involved actors. J Public Health. 2015;37(4):716-27. doi: 10.1093/pubmed/fdu102

2. Onda M, Imai H, Kataoka Y, Takamatsu M, Tanaka M, Tanaka $\mathrm{H}$, et al. A preliminary study about the relationship between workload and the outcomes of community pharmacists' home visiting service. Jpn J Soc Pharm. 2013;32(2):27. doi: $10.14925 / 32.2$

3. Rojas-Fernandez CH, Patel T, Lee L. An interdisciplinary memory clinic: A novel practice setting for pharmacists in primary care. Ann Pharmacother. 2014;48(6):78595. doi: 10.1177/1060028014526857

4. Nigro SC, Garwood CL, Berlie H, Irons $\mathrm{B}$, Longyhore D, McFarland MS, et al. Clinical pharmacists as key members of the patient-centered medical home: An opinion statement of the ambulatory care practice and research network of the american college of clinical pharmacy. Pharmacotherapy. 2014;34(1):96-108. doi: 10.1002/phar.1357

5. Ong KY, Cheen MHH, Chng JSG, Chen LL, Ng SM, Lim SH, et al. Effectiveness of a multidisciplinary home-based medication review program in reducing healthcare utilization among older adult Singaporeans: Home-based medication reviews for the elderly. Geriatr Gerontol Int. 2017;17(2):302-7. doi: 10.1111/ggi.1
2706

6. Tunpichart S, Sakulbumrungsil R, Somrongthong R, Hongsamoot D. Chronic care model for diabetics by pharmacist home health in Bangkok Metropolitan: A community based study. Int J Medicine Med Sci. 2012;4(4):90-6. doi: 10.5897/IJ MMS12.009

7. Boult C, Green AF, Boult LB, Pacala JT, Snyder C, Leff B. Successful models of comprehensive care for older adults with chronic conditions: Evidence for the institute of medicine's "retooling for an aging America" report: [see editorial comments by Dr. David B. Reuben]. J Am Geriatr Soc. 2009;57(12):2328-37. doi: 10.1111/j.1532-5415.2009.02571.x

8. Fredericksen RJ, Gibbons L, Brown S, Edwards TC, Yang FM, Fitzsimmons E, et al. Medication understanding among patients living with multiple chronic conditions: Implications for patientreported measures of adherence. Res Social Adm Pharm. 2018;14(6):540-4. doi: 10.1016/j.sapharm.2017.06.009

9. Hassali MA, Al-Tamimi S, Hashmi F, AlTamimi SK. Defining clinical pharmacy: A new paradigm. Pharm J. 2016 [Accessed on 31 December 2018]. Available from: http://www.pharmaceutical-journal.com/ opinion/comment/defining-clinical-phar macy-a-new-parad igm/20201798.article

10. Walus AN, Woloschuk DM. Impact of pharmacists in a community-based home care service: A pilot program. Can J Hosp Pharm. 2017;70(6):435-42. doi: 10.4212/ cjhp.v70i6.1718

11. Boles N, Gowac A. The role of the pharmacist in home healthcare. Home Healthc Now. 2017;35(1):55-6. doi: 10.1 097/NHH.0000000000000437

12. Markle-Reid M, Browne G, Gafni A, Roberts J, Weir R, Thabane L, et al. The effects and costs of a multifactorial and interdisciplinary team approach to falls 
prevention for older home care clients 'at risk' for falling: A randomized controlled trial. Can J Aging. 2010;29(01):139-61. doi: $10.1017 / \mathrm{S} 0714980809990377$

13. Chen JH, Ou HT, Lin TC, Lai ECC, Yang Kao YH. Pharmaceutical care of elderly patients with poorly controlled type 2 diabetes mellitus: A randomized controlled trial. Int J Clin Pharm. 2016;38 (1):88-95. doi: 10.1007/s11096-015-021 0-4

14. Sadeghi K, Mohammadi M, Najmeddin F, Mashayekhi M, Mojtahedzadeh M, Javadi $\mathrm{M}$, et al. Pharmacist-led medication review: Supports for new role of pharmacists. J Pharm Care. 2013;1(4):153-60.

15. BrulhartMI, WermeilleJP.Multidisciplinary medication review: Evaluation of a pharmaceutical care model for nursing homes. Int J Clin Pharm. 2011;33(3):54957. doi: 10.1007/s11096-011-9506-1

16. Milos V, Rekman E, Bondesson Å, Eriksson T, Jakobsson U, Westerlund $\mathrm{T}$, et al. Improving the quality of pharmacotherapy in elderly primary care patients through medication reviews: A randomised controlled study. Drugs Aging. 2013;30(4):235-46. doi: 10.1007/ s40266-013-0057-0

17. Azevedo M da GB de, Pedrosa RS, Aoqui CM, Martins RR, Nagashima Junior T. Effectiveness of home pharmaceutical interventions in metabolic syndrome: A randomized controlled trial. Braz J Pharm Sci. 2017;53(2):e16089. doi: 10.1590/s21 75-97902017000216089

18. Wouters H, Scheper J, Koning H, Brouwer C, Twisk JW, van der Meer $\mathrm{H}$, et al. Discontinuing inappropriate medication use in nursing home residents: A cluster randomized controlled trial. Ann Intern Med. 2017;167(9):609-17. doi: 10.7326/ M16-2729

19. Utaminingrum W, Pranitasari R, Kusuma AM. Pengaruh home care apoteker terhadap kepatuhan pasien hipertensi. Indones J Clin Pharm. 2017;6(4):240-6. doi: 10.15416/ ijcp2017.6.4.240

20. Larasanty LPF, Meilinayanti NML, Susanti NMP, Wirasuta IMAG. Pengaruh pelayanan kefarmasian residensial terhadap ketaatan dan luaran klinis pasien hipertensi. Indones J Clin Pharm. 2015;4(3):162-74. doi: 10.15416/ijcp.2015.4.3.162

21. Icwari NPWP, Wirasuta IMAG, Susanti NMP. Akseptabilitas pelayanan residensial kefarmasian pada pasien diabetes melitus tipe II tanpa komplikasi. J Farm Udayana. 2013;2(2):1-5.

22. Suryani NM, Wirasuta IMAG, Susanti NMP. Pengaruh konseling obat dalam home care terhadap kepatuhan pasien diabetes melitus tipe 2 dengan komplikasi hipertensi. Jurnal Farmasi Udayana. 2013; 2(3):6-12.

23. Leiva A, Moreno L, Duro RE, Serra F, Dagosto P, Iglesias AA, et al. Efficacy of a brief multifactorial adherence-based intervention in reducing blood pressure: A randomized clinical trial. Patient Prefer Adherence. 2014;8:1683-90. doi: 10.214 7/PPA.S66927

24. Kementerian Kesehatan Republik Indonesia. Peraturan Menteri Kesehatan Republik Indonesia Nomor 72 Tahun 2016 Tentang Standar Pelayanan Kefarmasian di Rumah Sakit. Jakarta: Kementerian Kesehatan Republik Indonesia; 2016.

25. Kementerian Kesehatan Republik Indonesia. Peraturan Menteri Kesehatan Republik Indonesia Nomor 73 Tahun 2016 Tentang Standar Pelayanan Kefarmasian diApotek. Jakarta: Kementerian Kesehatan Republik Indonesia; 2016.

26. Kementerian Kesehatan Republik Indonesia. Peraturan Menteri Kesehatan Republik Indonesia Nomor 74 Tahun 2016 Tentang Standar Pelayanan Kefarmasian di Puskesmas. Jakarta: Kementerian Kesehatan Republik Indonesia; 2016. 
27. Kementerian Kesehatan Republik Indonesia. Peraturan Menteri Kesehatan Republik Indonesia Nomor 67 Tahun 2015 Tentang Penyelenggaraan Pelayanan Kesehatan Lanjut Usia di Pusat Kesehatan Masyarakat. Jakarta: Kementerian Kesehatan Republik Indonesia; 2015.

28. Reidt S, Morgan J, Larson T, Blade MA. The role of a pharmacist on the home care team: A collaborative model between a college of pharmacy and a visiting nurse agency. Home Healthc Nurse. 2013;31 (2):80-7. doi: 10.1097/NHH.0b013e3182 $778 \mathrm{f} 5 \mathrm{f}$

29. Loganathan M, Singh S, Franklin BD, Bottle A, Majeed A. Interventions to optimise prescribing in care homes: systematic review. Age Ageing. 2011;40 (2):150-62. doi: 10.1093/ageing/afq161

30. Hogg W, Lemelin J, Dahrouge S, Liddy C, Armstrong CD, Legault F, et al. Randomized controlled trial of anticipatory and preventive multidisciplinary team care. Can Fam Physician. 2009;55 (12):e76-85.

31. Setter SM, Corbett CF, Neumiller JJ, Gates BJ, Sclar DA, Sonnett TE. Effectiveness of a pharmacist-nurse intervention on resolving medication discrepancies for patients transitioning from hospital to home health care. Am J Health Syst Pharm. 2009;66(22):2027-31. doi: 10.2146/ajhp 080582

32. Collier IA, Baker DM. Implementation of a pharmacist-supervised outpatient diabetes treatment clinic. Am J Health Syst Pharm. 2014;71(1):27-36. doi: 10.2 146/ajhp130200

33. Biswas A, Sinha N, Ray K, Tripathi SK. A study on drug use and medication management perspectives among elderly and the impact of professional oversight. J Clin Diagn Res. 2018;12(5):FC01-07. doi: 10.7860/JCDR/2018/32786.11518

34. Olesen C, Harbig P, Buus KM, Barat I, Damsgaard EM. Impact of pharmaceutical care on adherence, hospitalisations and mortality in elderly patients. Int J Clin Pharm. 2014;36(1):163-71. doi: 10.1007/ s11096-013-9898-1

35. Porter AK, Taylor SR, Yabut AH, Al-Achi A. Impact of a pill box clinic to improve systolic blood pressure in veterans with uncontrolled hypertension taking 3 or more antihypertensive medications. J Manag Care Spec Pharm. 2014;20(9):905 -11. doi: 10.18553/jmcp.2014.20.9.905

36. Choe HM, Farris KB, Stevenson JG, Townsend K, Diez HL, Remington TL, et al. Patient-centered medical home: Developing, expanding, and sustaining a role for pharmacists. Am J Health Syst Pharm. 2012;69(12):1063-71. doi: 10.21 46/ajhp110470

37. Elliott RA, Lee CY, Beanland C, Goeman DP, Petrie N, Petrie B, et al. Development of a clinical pharmacy model within an Australian home nursing service using co-creation and participatory action research: the Vi siting $\mathrm{P}$ harmacist (ViP) study. BMJ Open. 2017;7(11):e018722. doi: 10.1136/bmjopen-2017-018722

38. Leendertse AJ, de Koning GHP, Goudswaard AN, Belitser SV, Verhoef M, de Gier HJ, et al. Preventing hospital admissions by reviewing medication (PHARM) in primary care: An open controlled study in an elderly population. J Clin Pharm Ther. 2013;38(5):379-87. doi: 10.1111/jcpt.12069

39. Basheti IA, Qunaibi EA, Bulatova NR, Samara S, AbuRuz S. Treatment related problems for outpatients with chronic diseases in Jordan: The value of home medication reviews. Int J Clin Pharm. 2013;35(1):92-100. doi: 10.1007/s11096 -012-9713-4

40. Cheen MHH, Goon CP, Ong WC, Lim PS, Wan CN, Leong MY, et al. Evaluation of a care transition program with pharmacistprovided home-based medication review 
for elderly Singaporeans at high risk of readmissions. Int J Qual Health Care. 2017;29(2):200-5. doi: 10.1093/intqhc/m Zw150

41. Elliott RA, Martinac G, Campbell S, Thorn J, Woodward MC. Pharmacist-led medication review to identify medicationrelated problems in older people referred to an aged care assessment team. Drugs Aging. 2012;29(7):593-605. doi: 10.100 7/BF03262276

42. Andreassen LM, Kjome RLS, Sølvik UØ, Houghton J, Desborough JA. The potential for deprescribing in care home residents with type 2 diabetes. Int J Clin Pharm. 2016;38(4):977-84. doi: 10.1007/ s11096-016-0323-4

43. Kilcup M, Schultz D, Carlson J, Wilson B. Postdischarge pharmacist medication reconciliation: Impact on readmission rates and financial savings. J Am Pharm Assoc. 2013;53(1):78-84. doi: 10.1331/ JAPhA.2013.11250

44. Cipolle RJ, Strand LM, Morley PC. Pharmaceutical care practice: The patient-centered approach to medication management services. $3^{\text {rd }}$ edition. United States: McGraw-Hill; 2012. 